\title{
Permanganate Oxidation mechanisms of Alkylarenes
}

\author{
Mukul Chauhan \\ Department of Chemistry, College of natural and computational Science Ambo University, Ethiopia (Africa)
}

\begin{abstract}
Permanganate oxidation of benzaldehyde and p-nitrobenzaldehyde goes by two paths, i.e. a major one which is responsible for the normal oxidation giving good second order kinetic and minor path which involves a very small percent of a radical species formed by hydrogen atom abstraction by the permanganate ion. A mechanism involving Hydrogen atom abstraction by permanganate from the alkoxide ion is thus favoured in the permanganate oxidation of p-nitrophenyltrifluoromethylcarbinol. Oxidations of alkylarenes by $n \mathrm{Bu}_{4} \mathrm{NMnO}_{4}$ in toluene solvent. Toluene is oxidized to benzoic acid and a small amount of benzaldehyde.The kinetics of the reactions, monitored by UV/vis spectrometry; show that the initial reactions are first order in the concentrations of both $n \mathrm{nB} u_{4} \mathrm{NMnO}_{4}$ and substrate. No induction periods are observed. The rate-limiting step in all of the reactions is hydrogen atom transfer from the substrate to a permanganate oxo group. The ability of permanganate to abstract a hydrogen atom is explained on the basis of its ability to form an $80 \pm 3 \mathrm{kcal} / \mathrm{mol}$ bond to $\mathrm{H} \bullet$, as calculated from a thermo chemical cycle. Rates of $\mathrm{H} \bullet$ abstraction by $\mathrm{nBu}_{4} \mathrm{NMnO}_{4}$ correlate with rates of abstraction by oxygen radicals.
\end{abstract}

Keywords: Hydride ion transfer,Hydrogen atom transfer,Electron abstraction,Oxygen transfer,Aldehydate ion,trifluoromethylcarbinol

\section{Introduction}

The selective oxidation of hydrocarbons is a fundamental transformation in chemistry, important in a wide range of areas from biological to industrial chemistry.[31] The classic examples of stoichiometric hydrocarbon oxidation by metal- oxo species are those of permanganate and chromium(VI) reagents, which have been used for this purpose for over a century.[32] Permanganate has been widely used as a strong, easily handled, readily available, and versatile oxidant, reacting with alcohols, alkenes, aldehydes, saturated $\mathrm{C}-\mathrm{H}$ bonds, and other function- alities.[7,33,34] The lack of selectivity of permanganate is due, at least in part, to its ability to react readily by either one-electron or two-electron pathways, and its conversion to even stronger oxidants such as " $\mathrm{MnO}_{3}{ }^{+}$".[35]

The first example of alkyl arenes with molecular oxygen was published by Ciamician and Silber[1] they allowed toluene, o-xylene, p-xylene, m-xylene for about a year to be influenced by oxygen and Sun light. The corresponding mono carboxylic acid was obtained as main product. IG-Farben produced a method for oxidation of ethyl benzene ${ }^{2}$ The oxidation carried out at $120-130{ }^{\circ} \mathrm{C}$ in the presence of $\mathrm{Mn}$-acetate, gave a mixture of acetaphenone and phenylmethylcarbinol. $\mathrm{KMnO}_{4}$ is stable for months in neutral solution, when kept in dark[5] but decomposition is noticeable in acids[6] or in alkaline solution[23] The degradation of organic molecules proceeds via the breakage of covalent bond while manganese undergoes reduction to lower valency state via a number of electron transitions with certain reductants in acidic solution, five electrons change may occur-

$$
\mathrm{MnO}_{4}+8 \overline{\mathrm{H}}+5 \mathrm{e} \rightleftharpoons \stackrel{++}{\mathrm{Mn}}+4 \mathrm{H}_{2} \mathrm{O}
$$

In weakly acids, neutral and weakly alkaline solution, there are three electrons change-

$$
\mathrm{MnO}_{4}+4 \overline{\mathrm{H}}+3 \mathrm{e}-\rightleftharpoons \mathrm{MnO}_{2}+4 \mathrm{H}_{2} \mathrm{O}
$$

And in strong alkaline solution, only one electron change-

$$
\mathrm{MnO}_{4}+1 \mathrm{e}=\mathrm{MnO}_{4}
$$

Generally inorganic substance reduces acid permanganate to $\mathrm{Mn}^{+2}$. Whereas organic substance (containing oxidizable hydrogen) stop the reduction at the manganese di-oxide state.

\section{Experimental, results and discussion}

Oxy-anion of manganese has importance in many reduction mechanisms. The purple tetrahedral Permanganate ion is known to decompose in alkaline solution according to the equation-

$$
4 \mathrm{MnO}^{-}+4 \overline{\mathrm{OH}} \longrightarrow 4 \mathrm{MnO}_{4}+2 \mathrm{H}_{2} \mathrm{O}+\mathrm{O}_{2}
$$


Rate of reaction under various conditions of temperature and concentration of alkali studied by Fergussion and co-workers [23] but they did not produce any mechanism. Later Stamm[7] suggested that the equilibrium

$$
\begin{aligned}
& \mathrm{MnO}_{4}+\mathrm{H}_{2} \rightleftharpoons \mathrm{MnO}_{4} \rightleftharpoons \stackrel{+}{\mathrm{H}}+\stackrel{\bullet}{\mathrm{OH}} \\
& \mathrm{MnO}_{4}+\overline{\mathrm{O}} \rightleftharpoons \mathrm{MnO}_{4} \rightleftharpoons \mathrm{HO}^{\circ}
\end{aligned}
$$

Occur in alkaline solution of potassium Permanganate and this was supported by the fact that in alkaline solution radioactive exchange between the $\mathrm{MnO}_{4}$ and $\mathrm{MnO}_{4}{ }^{2}$ ion is immeasurably rapid and oxidation of a substrate taking place by free hydroxyl radical.

\section{MECHANISM ON ALKALINE DECOMPOSITION OF PERMANGANATE}

Kinetic studies and mechanism on the alkaline decomposition of permanganate made by Symons ${ }^{8}$

\begin{tabular}{|c|c|c|c|c|c|}
\hline $\mathrm{MnO}_{4}$ & $+\quad \overline{\mathrm{O}} \mathrm{H}$ & & $=\quad \mathrm{MnO}_{4}$ & + & HO \\
\hline HO̊ & $\overline{\mathrm{OH}}$ & & $\Longrightarrow \mathrm{H}_{2} \mathrm{O}$ & + & $\mathrm{O}^{\bullet-}$ \\
\hline $\mathrm{MnO}_{4}$ & HŌ & $+\dot{O}^{-}$ & $=\mathrm{MnO}_{4}$ & + & $\mathrm{HO}_{2}$ \\
\hline $\mathrm{MnO}_{4}$ & $\mathrm{HO}_{2}$ & & $=\mathrm{MnO}_{4}$ & + & $\mathrm{HO}_{2}$ \\
\hline $\mathrm{HO}_{2}$ & $\overline{\mathrm{OH}}$ & & $=\mathrm{O}_{2}^{-}$ & + & $\mathrm{H}_{2} \mathrm{O}$ \\
\hline$\overline{\mathrm{O}}_{4}$ & $+\overline{\mathrm{O}_{2}}$ & & $\rightleftharpoons \mathrm{MnO}_{4}$ & + & $\mathrm{O} 2$ \\
\hline
\end{tabular}
mechanisms involving a series of electron and protons transfer-

Symons[8] states that the usual mode of oxidation of alkaline permanganate by attack on the substrate by hydroxyl radicals or hydroxyl radical ions. He gives good evidence for this by initiating polymerization of acrylonitrile and styrene in alkaline solution of permanganate. This conclusion is doubted by Drummond and waters[9] Who shown that when diethyl ether, dioxane, t-butanol,propionic, succinic and adipic acids are oxidized by free radicals but not attacked by alkaline permanganate[24] conversely acetone, malonic acid and formic acid are attacked by alkaline permanganate but not by free hydroxyl radical.

\section{OXIDIZING POWER OF MANGANATE}

Waters and co-workers [9,10] investigated stability and oxidizing power of manganate.[5,34]

$$
2 \mathrm{H}_{2} \mathrm{O}+3 \mathrm{MnO}_{4} \longrightarrow \mathrm{MnO}_{2}+2 \mathrm{MnO}_{4}+4 \overline{\mathrm{OH}}
$$

Pode and waters[10] postulated a mode of oxidation by strongly alkaline permanganate involving one electron steps.

$$
\begin{aligned}
& \mathrm{MnO}_{4}+\overline{\mathrm{O}}_{2} \mathrm{H} \longrightarrow \mathrm{MnO}_{4}+\mathrm{HO}_{2} \\
& \mathrm{MnO}_{4}+\mathrm{HO}_{2} \longrightarrow \stackrel{+}{\bar{O}}_{4}+\stackrel{+}{\mathrm{H}}+\mathrm{O}_{2}
\end{aligned}
$$

And each of these oxyanions of manganese can be identified by spectrophotometically as the reduction takes place. Wiberg and Stewart[11] found that manganate and permanganate oxidized substituted benzaldehyde at the same rate. Since the hydroxyl radical is postulated in the oxidation process. Decomposition by manganous salts is known as Guyards reaction[53] and occurs in neutral and alkaline solution.

$$
2 \mathrm{MnO}_{4}+3 \mathrm{Mn}^{++}+4 \overline{\mathrm{OH}} \rightleftharpoons 5 \mathrm{MnO}_{2}+2 \mathrm{H}_{2} \mathrm{O}
$$

The cation $\mathrm{Mn}^{3+}$ is involved in the rate determining step of many reactions in the acid solution, but is stable only in concentrated sulphuric acid[38] with fast disproportionation occurring at lower acidities.

$$
2 \stackrel{++-}{2 \mathrm{Mn}} \rightleftharpoons \stackrel{++++}{\mathrm{Mn}}+\mathrm{Mn}^{++}
$$

It is possible however to stabilize solutions of $\mathrm{Mn}^{3+}$ with complexing agents such as pyrophosphates, which makes them more suitable as oxidizing agents in the $\mathrm{pH}$ regions. Waters and co-workers $[20,25,26]$ have extensively investigated that $\mathrm{Mn}^{3+}$ oxidation of a number of organic substrates using this technique. Tronov[12] determined rate of reaction between $\mathrm{KMnO}_{4}$ and a number of alcohol and aldehydes but did not postulate any mechanism. It is found that the oxidation of formaldehyde with permanganate is a base catalyzed.[13] 
Drummond and Waters[9] oxidized aldehyde, alcohol, ketones and acids with permanganate and presented a little discussion in term of mechanism.

\section{III.SOME MECHANISMS OF PERMANGANATE OXIDATION OF ALKYLARENES}

\section{A. Oxidation of 2,2,2-trifluoroethanol}

Quantitative conversion of branched chain carboxylic acid to their corresponding hydroxyl acids were found[14] and later co-workers postulated a mechanism involving radical abstraction of a tertiary hydrogen atom by hydroxyl radicals. The oxidation mechanism [4] of alcohol and its deuterium analogue throughout the $\mathrm{pH}$ region and compared with 2,2,2-trifluoroethanol and other substituted alcohols which ionize in the $\mathrm{pH}$ region, Fluoral hydrate is unique in that it has two acidic hydrogen both can ionize. Deuterium isotope effect were change with nature of substrate, furthermore activation parameters and a positive salt effect show that the transition state in formed from species like charge. These results indicate the hydride ion transfer to the permanganate ion is the rate determining step and mechanism was-

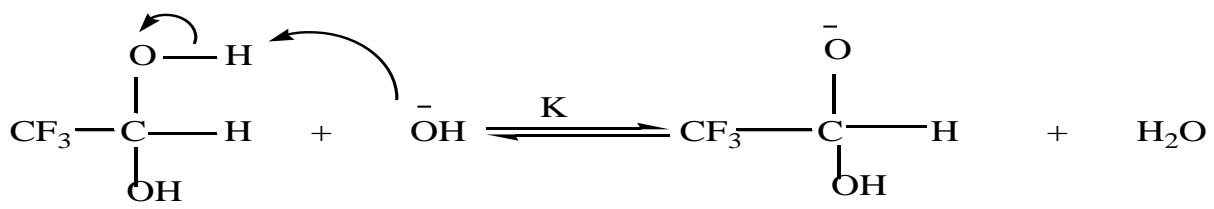

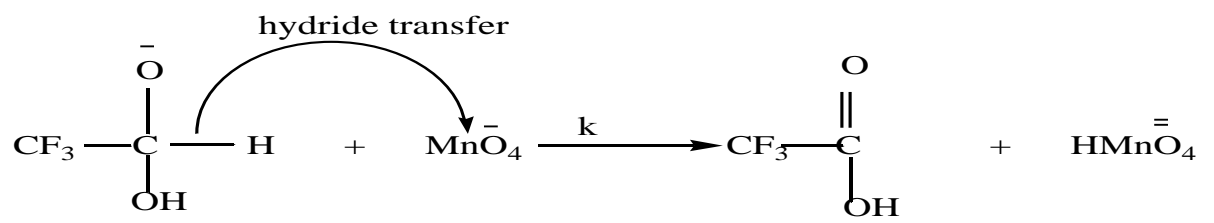

$$
\mathrm{HMnO}_{4}+\mathrm{MnO}_{4} \longrightarrow 2 \mathrm{MnO}_{4}+\overline{\mathrm{H}}
$$

And in strong $\mathrm{pH}$ region (12-14) the rate determining step would be -

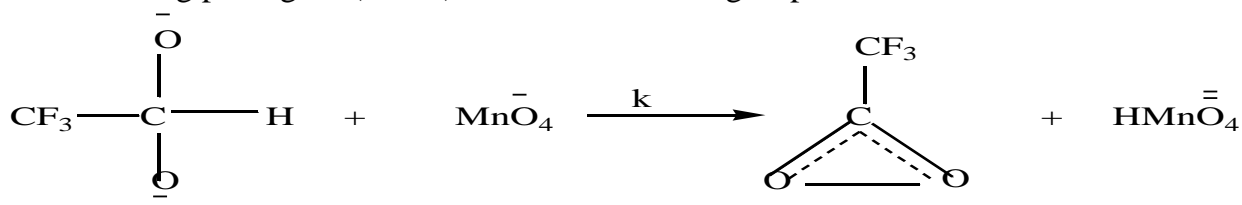

But it was kinetically impossible [55] to distinguish between a mechanism involving the aldehydrol anion as a discreet intermediate and a concerted mechanism involving hydroxyl ion and aldehyde hydrate. Hence termolecular mechanism are also considered-

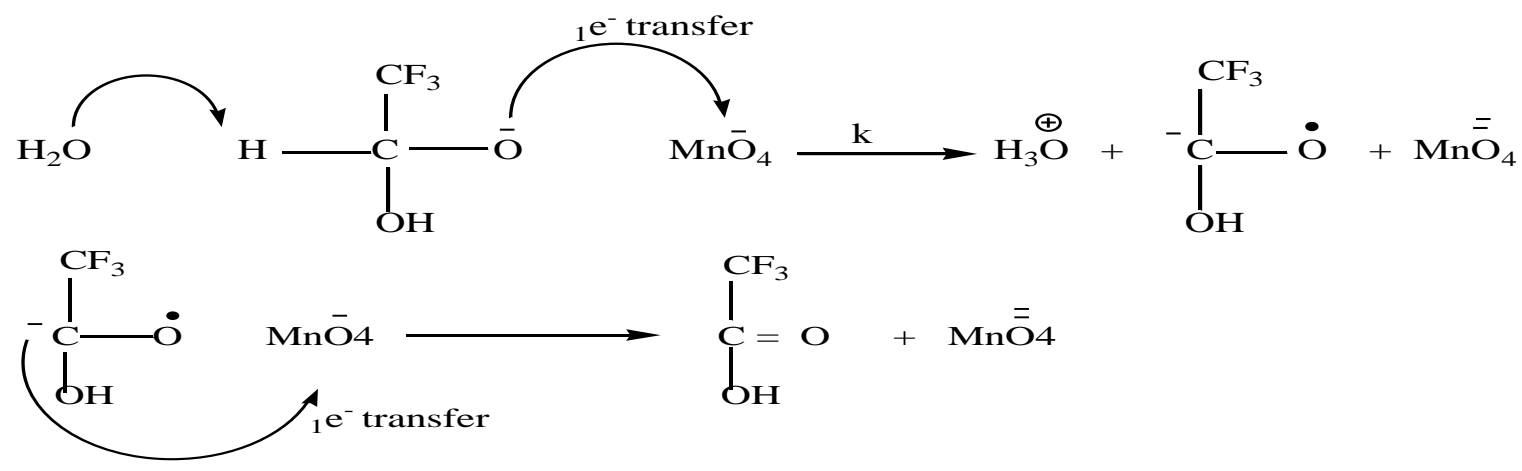

\section{B. Oxidation of benzaldehyde}

The permanganate oxidation of benzeldehyde, Tompkins[15] reported a linear increase in rate with hydroxide ion concentration over a very limited range although in basic solution the rate in a given run was found to drop with time and he proposed the following mechanism- 


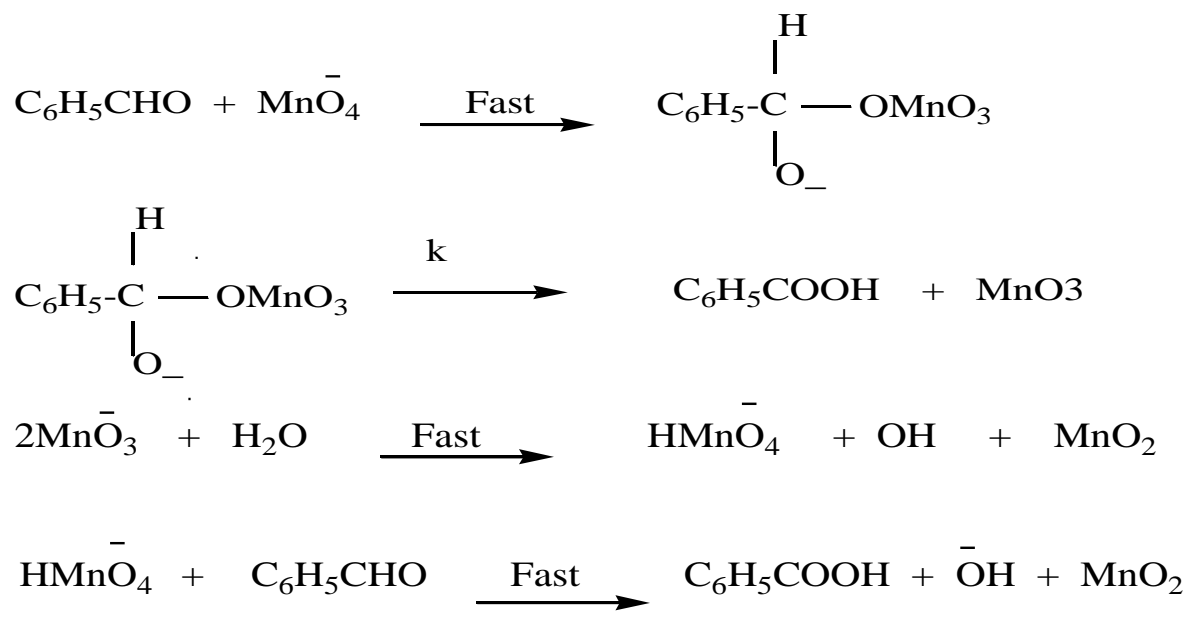

Wiberg and stewart[11] used deuterium and oxygen-18 labelling technique and found substantial isotope effect in weakly acidic region. This effect decreased with increasing $\mathrm{pH}$ as did the oxygen-18 transfer from permanganate to substrate and the reaction found to be acid catalyzed.
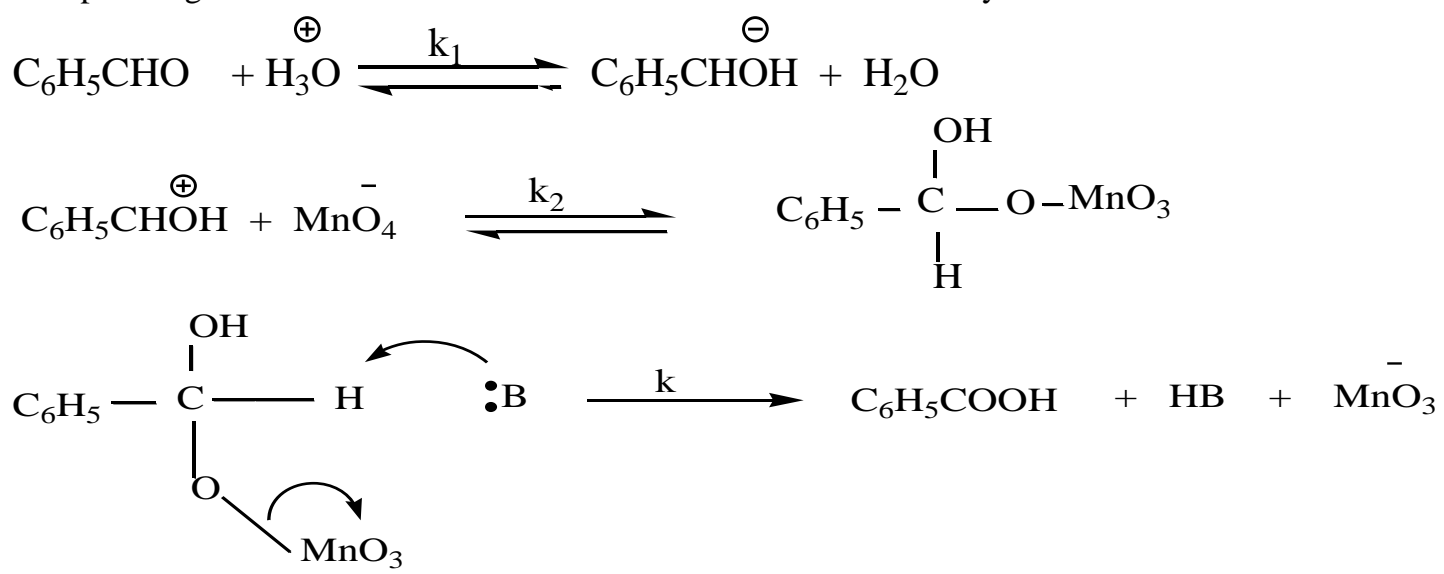

$$
3 \mathrm{MnO}_{3}+\mathrm{H}_{2} \mathrm{O} \underset{\text { Fast }}{\longrightarrow} 2 \mathrm{MnO}_{2}+\mathrm{MnO}_{4}+2 \mathrm{OH}
$$

A Hammett plot shown a good linear relation with a negative $\sigma$ value $(\sigma=$ Hammett substituent constant) one would expect the rate determining step to have a positive $\sigma$ value, since an electron withdrawing group would facilitate the abstraction of a proton in this step. Equilibrium forming the intermediate ester is proposed having a negative $\sigma$ value, which is larger in magnitude than that for the rate determining step.

The original proposal of Tompkins [15] was that aldehydate ion could react with permanganate ion by a hydride shift and the effect of substituent on the rate would be in agreement of the stability of the ion. However in order to explain the dependence of the rate on the square root of the hydroxyl concentration then a free radical chain mechanism involving hydroxyl radical was suggested. Furthermore manganate and permanganate were found to react with benzaldehyde with rate of the same order of magnitude. This support a radical mechanism as one would expect a hydride shift to be much slower for magnitude in view of the double negative charge on the ion.

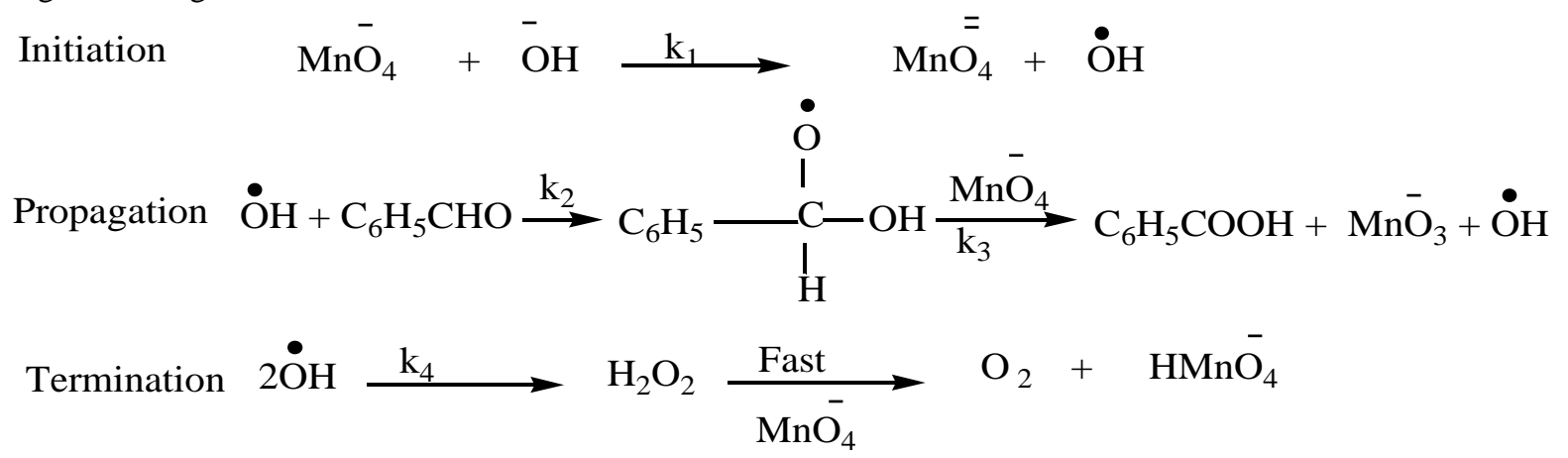

Stewart [17] used deuterium substitution and oxygen-18 exchange shown that the C-H bond is broken in the rate 
determining step. The rate showed a dependence on the hydroxyl concentration and positive salt effect.

According to this mechanism involving a hydride ion transfer from the benzhydrylate anion to permanganate ion was postulated-

$$
\begin{aligned}
& \mathrm{Ph}_{2} \mathrm{CHOH}+\overline{\mathrm{OH}} \rightleftharpoons \mathrm{Ph}_{2} \mathrm{CHO}+\mathrm{H}_{2} \mathrm{O} \text { Fast } \\
& \mathrm{Ph}_{2} \mathrm{CHO}+\mathrm{MnO}_{4} \longrightarrow \mathrm{Ph}_{2} \mathrm{C}=\mathrm{O}+\mathrm{HMnO}_{4} \quad \text { Slow } \\
& \mathrm{HMnO}_{4}+\mathrm{MnO}_{4}+\overline{\mathrm{OH}} \longrightarrow 2 \mathrm{MnO}_{4}+\mathrm{H}_{2} \mathrm{O} \quad \text { Fast }
\end{aligned}
$$

\section{Oxidation of Aryl-trifluoromethylcarbinols}

ionized

Further Aryl Trifluoromethylcarbinols oxidation proved to the satisfactory since they are highly

$$
\mathrm{ArCHOHCF}_{3}+2 \mathrm{MnO}_{4}+2 \overline{\mathrm{OH}} \longrightarrow \stackrel{\stackrel{\mathrm{O}}{\|}}{\longrightarrow} \mathrm{Ar}-\stackrel{\mathrm{C}}{-}-\mathrm{CF}_{3}+2 \mathrm{MnO}_{4}+2 \mathrm{H}_{2} \mathrm{O}
$$

Stewart [17] on the Benzhydrol oxidation alcoholate ion is the reactive species if this is so then it should be possible to observe a levelling off of the rate in the region where the alcohol is mostly fully ionized, the rate should be determined by the alcoholate ion present. This has been confirmed.[18,19] Further the observation of positive salt effect, a large negative entropy of activation and a large deuterium isotope effect $(\mathrm{kH} / \mathrm{kD}=16)$ are indicative of a hydride ion transfer mechanism,
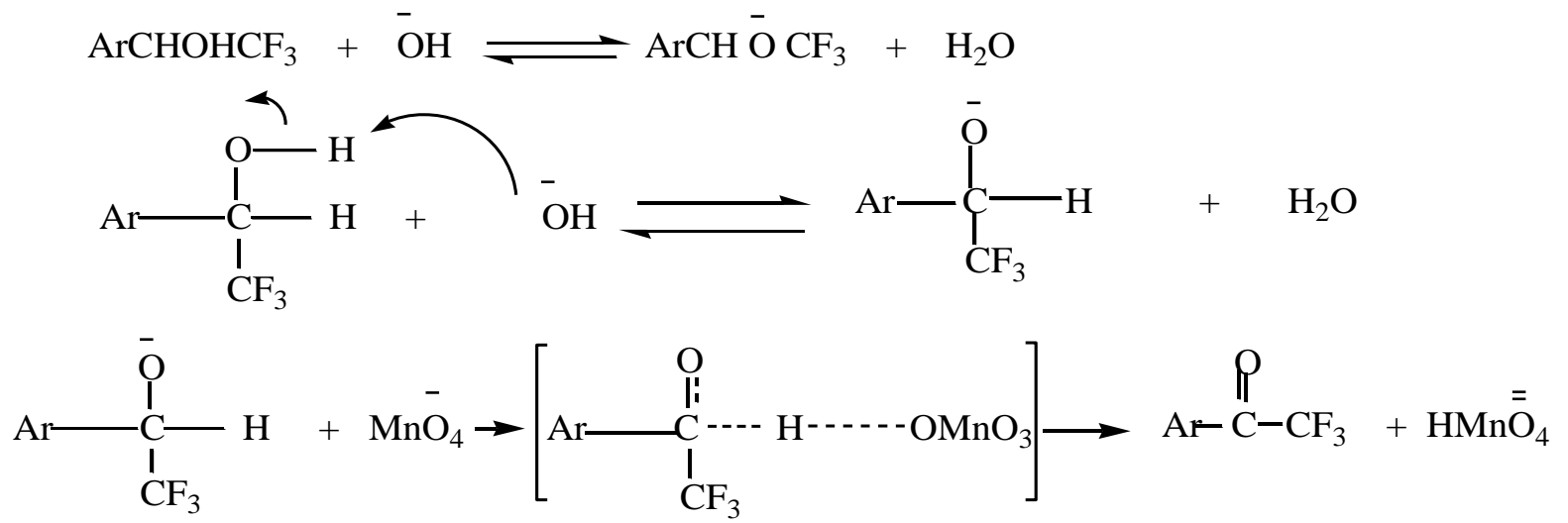

Normal deuterium isotope effects which result from a loss of $\mathrm{C}-\mathrm{H}$ stretching modes in the transition state are less than half this size at the same temperature.[8] The large effect is observed here is postulated as due to the loss of bending as well as stretching modes in the transition states. The effect of nuclear substitution was found to be slight and this is not in accord with the above mechanism. A hydride transfer from the alkoxide to permanganate should result in a negative $\sigma$ value. For example a p-methoxy substituent should accelerate and a p-nitro group retard the process. However the reaction rate was found to be only slightly affected by nuclear substitution and further more the small variations in rate which did occur were not related linearly to the Hammett substituent constant $(\sigma)$.

The following explanations have been presented. Firstly a simple hydride transfer may in fact be occurring with the electronic effect of a distant drop in the molecule being unimportant. Secondly, two different processes with different electronic requirements may be occurring, one with a positive and the other with a negative $\sigma$ value. Thirdly one of several termolecular mechanisms may be taking place. An example of which is shown below- 


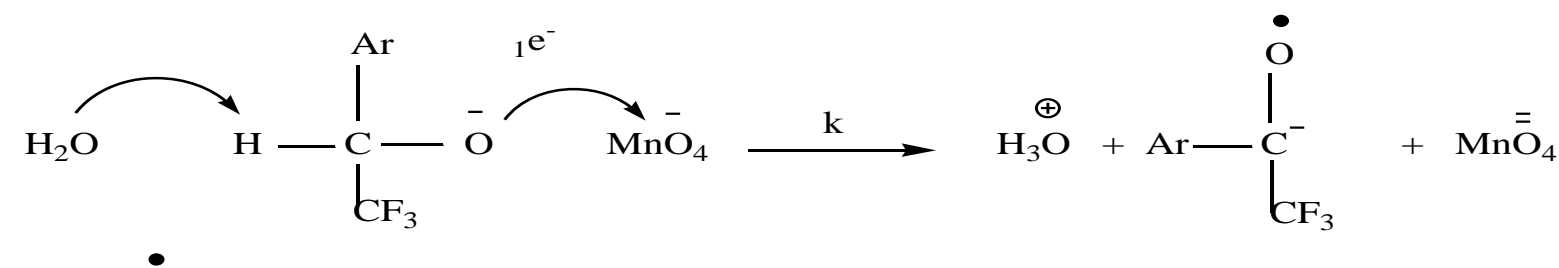

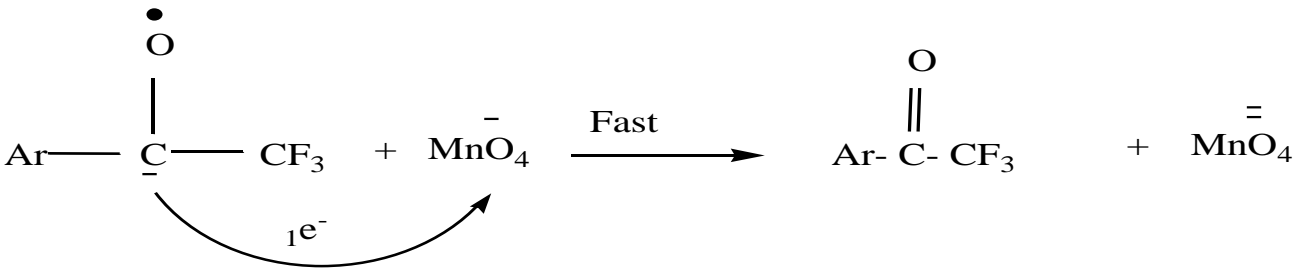

\section{Oxidation of toluene with $\mathrm{nBu}_{4} \mathrm{NMnO}_{4}$}

Kimberly and co-workers [29] explained the hydrogen atom abstraction by permanganate in oxidation of alkylarenes by $\mathrm{nBU}_{4} \mathrm{NMnO}_{4}$ [39] in toluene solvent. Toluene oxidized to benzoic acid and a small amount of benzaldehyde. The kinetic of the reaction maintaining by Uv/Vis spectroscopy, show that the initial reactions are first order in the concentration of both $\mathrm{nBU}_{4} \mathrm{NMnO}_{4}$ and substrate. Here the use of organic solvent allow the substrate and solvent to be the same and avoids some of the complications of aqueous permanganate reactions, such as decomposition at high[40] and autocatalysis at low[21] $\mathrm{pH}$. Involvement of water in the rate determining step [41] and limited solubility of the organic substrate of interest [11] . There is previous report of C-H bond oxidation by organic soluble permanganate salt. It is concluded that the first step in these reactions is abstraction of a hydrogen atom by permanganate, as it has found in related $\mathrm{CrO}_{2} \mathrm{Cl}_{2}$ The data support that the occurrence and rate of these reactions are a direct result of the $\mathrm{O}-\mathrm{H}$ bond formed on addition of a hydrogen atom to the oxidant.

Kimberly [29] studied that manganese undergoes a three electron change from $\mathrm{Mn}$ (VII) to $\mathrm{Mn}$ (IV) and the substrate oxidized by two, four or six electrons. For instance toluene to benzoic acid is a six electron oxidation. The idealized stoichiometry is given in equation-(1)

$$
2{ }^{\mathrm{n}} \mathrm{Bu}_{4} \mathrm{NMnO}_{4}+\mathrm{C}_{6} \mathrm{H}_{5} \mathrm{CH}_{3} \longrightarrow 2 \mathrm{MnO}_{2}+{ }^{\mathrm{n}} \mathrm{Bu}_{4} \stackrel{+}{\mathrm{N}} \mathrm{C}_{6} \mathrm{H}_{5} \mathrm{COO}+{ }^{\mathrm{n}} \mathrm{Bu}_{4} \mathrm{NOH}+\mathrm{H}_{2} \mathrm{O}
$$

The reaction closely follow the second order rate law as equation (2)

$$
\mathrm{d}\left[\mathrm{MnO}_{4}\right] / \mathrm{dt}=\mathrm{k}_{2}\left[{ }^{\mathrm{n}} \mathrm{Bu}_{4} \mathrm{NMnO}_{4}\right] \text { [substrate] }
$$

The rate expression equation-2 and the primary isotopic effect imply that the rate determining step of these reactions is bimolecular attack of permanganate on a substrate $\mathrm{C}-\mathrm{H}$ bond. There is no support for the suggestion that other manganese species are involved in the initial hydrocarbon activation. Similar conclusion were reached by Brauman and Pandell [42] in their study of the oxidation of $\gamma$-phenylvaleric acid in aqueous base and by Wiberg and Fox [43] in their studies of p-sec-butylbenzoic acid and 4-methylhexanoic acid in neutral and basic aqueous solutions. Outer-sphere electron transfer from arene to permanganate (equation-3) cannot be the initial step in these reactions.

$$
\mathrm{MnO}_{4}+\mathrm{C}_{6} \mathrm{H}_{5} \mathrm{CH}_{3} \longrightarrow \stackrel{\overline{M n O}}{4}_{4}+\mathrm{C}_{6} \mathrm{H}_{5} \mathrm{CH}_{3}^{\bullet+}
$$

But It should be more difficult to form the radical cation of 4-methylbenzophenone than to form that of toluene, yet this substrate is oxidized faster than toluene. Permanganate has a less positive redox potential in toluene than in water $\left(\mathrm{E}^{0}=+0.56 \mathrm{~V}\right.$ vs NHE $)[44]$ and formation of the toluene radical cation would be less favourable in toluene solvent than in acetonitrile $\left(\mathrm{E}^{0}>+2.5 \mathrm{~V}\right.$ vs NHE) [45] Therefore on the basis of the aqueous and acetonitrile potentials, outer sphere electron transfer is at least $1.9 \mathrm{~V}$ or $44 \mathrm{kcal} / \mathrm{mol}$ uphill in toluene. Since this is larger than the observed $\Delta \mathrm{G}^{\ddagger}$ of $26 \mathrm{kcal} / \mathrm{mol}$. So equation-3 cannot be the rate determining step. Put another way, the equilibrium constant for electron transfer is $<10^{-32}$ which implies on the basis of the forward rate constant of $10^{-6} \mathrm{M}^{-1} \mathrm{~s}^{-1}$, that the reverse reaction(back electron transfer) would have to proceed at the impossible bimolecular rate of $10^{-6} \mathrm{M}^{-1} \mathrm{~s}^{-1}$ ( NHE = Normal Hydrogen Electrode $)$

Rate limiting $\mathrm{C}-\mathrm{H}$ bond cleavage could occur by proton, hydrogen atom or hydride transfer to permanganate oxo group or by [2+2] addition across a $\mathrm{Mn}-\mathrm{O}$ bond. Proton transfer can be immediately dismissed given the very low acidity of toluene and the low basicity of permanganate. [2+2] addition to metal oxo bonds has been suggested on the basis of ab initio calculations of $\mathrm{CrO}_{2} \mathrm{Cl}_{2}$ reactions [46] and experimental studies of manganate reactions. [47] The Hydride transfer from organic substrates to permanganate is well 
precedent, most clearly in the oxidation of alcohols [17] and has been proposed for the oxidation of toluene by $\mathrm{MnO}_{4}^{-}$in water [41]. Abstraction of $\mathrm{H}^{-}$from toluene would form $\mathrm{HMnO}^{2-}$ and benzyl cation (equation-4), an unlikely process given the observed substituent effects. $\mathrm{p}$-Xylene is only three times more reactive than toluene while it should be much more reactive. $\mathrm{p}$-Chlorotoluene and 4-methylbenzophenone react faster than toluene but should react much more slowly. In addition, the formation of higher-charged species such as benzyl cation is unfavourable in such a nonpolar solution.

$$
\mathrm{MnO}_{4}+\mathrm{C}_{6} \mathrm{H}_{5} \mathrm{CH}_{3} \longrightarrow \mathrm{HMnO}_{4}+\mathrm{C}_{6} \mathrm{H}_{5} \mathrm{CH}_{2}^{+}
$$

Rate-limiting hydrogen atom transfer from the substrate (equation-5) to a permanganate oxo group is consistent with all of the experimental evidence. This is probably the most commonly proposed mechanism for permanganate oxidations of $\mathrm{C}-\mathrm{H}$ bonds.[11,33,34,48,84] The lack of a solvent effect is characteristic of Radical reactions [49] and is not consistent with polar

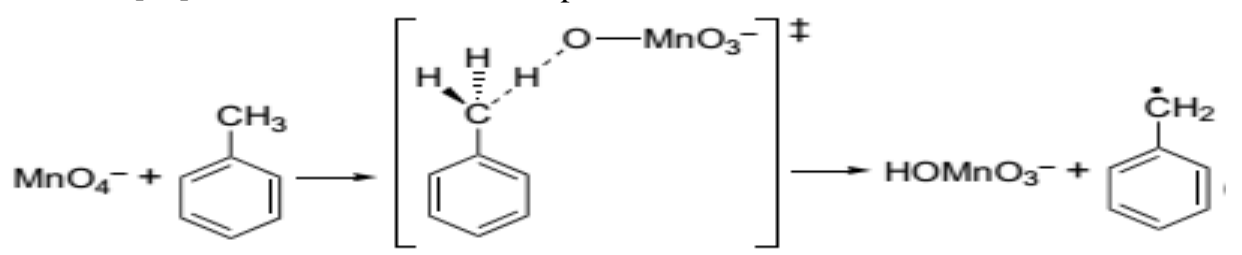

transition states or products. The observed influence of added $\mathrm{O} 2$ is an indicator of radical intermediates (equation-5).

\section{Discussion}

Hydrogen atom abstraction reactions exhibit small substituent effects and often do not show a correlation with Hammett $\sigma$ or $\sigma+$ values. [50, 85] Previous a larger substituent effects are observed because Permanganate is a slower and more selective hydrogen atom abstractor than $\mathrm{tBuOO}$ - The primary isotope effects are consistent with this mechanism, although the measured $\mathrm{kH} / \mathrm{kD}$ values are not the same as the isotope effects for the $\mathrm{H} \bullet$ transfer step. [29]

Kimberly. A. And co-workers [29] postulated that permanganate and relative oxidants can abstract hydrogen atom $\left(\mathrm{H}^{\bullet}\right)$ from organic substrate because of the strong bond they form on addition of Hydrogen atom.[56,57,58] Kimberly's [29] data also support this hypothesis. These co-workers [29] perspectives based on enthalpy change contrasts with the standard chemical intuition that a reagent needs to be radical in order to perform hydrogen atom abstraction. This intuition may be reflected in many proposed mechanism of hydrocarbon oxidation, from metalloenzymes to industrial heterogeneous catalysts. [31,59,60,61,67] Permanganate does not fit in this intuition because it is closed shell species. Whose lowest lying triplet state lies roughly $1800 \mathrm{~cm}^{-1}(51 \mathrm{kcal} / \mathrm{mol})$ above the ground state. [62] Since this energy is much larger than the observed energies of activation, a triplet state cannot be a intermediate in the reactions. It should be noted that it is spin allowed for two diamagnetic to react and form a singlet radical pair as in equation-5. Examples of hydrogen atom transfer between closed shell organic molecules have been described by Ruchardt and others $[63,64,65]$ Scheme-1

$$
\begin{aligned}
& \mathrm{MnO}_{4} \quad(\mathrm{aq})+\overline{\mathrm{e}} \longrightarrow \mathrm{MnO}_{4}(\mathrm{aq}) \\
& \left.1 / 2 \mathrm{H}_{2}(\mathrm{~g}) \longrightarrow \stackrel{+}{\mathrm{H}}(\mathrm{aq})+\stackrel{-}{\mathrm{e}}\right\} \quad \mathrm{E}^{0}=0.564 \mathrm{~V} \\
& \stackrel{=}{\mathrm{MnO} 4}(\mathrm{aq})+\stackrel{+}{\mathrm{H}}\left(\stackrel{\mathrm{aq}}{\longrightarrow} \quad \mathrm{HMnO}^{2}(\mathrm{aq}) \quad \mathrm{pKa}=7.4\right. \\
& { }^{\bullet} \mathrm{H}(\mathrm{aq}) \longrightarrow 1 / 2 \mathrm{H}_{2}(\mathrm{~g}) \quad \mathrm{C}=-57 \pm 2 \mathrm{kcal} / \mathrm{mol}
\end{aligned}
$$

$$
\begin{aligned}
& \mathrm{MnO}_{4}(\mathrm{aq})+\mathrm{H}^{\bullet}(\mathrm{aq}) \longrightarrow \mathrm{HMnO}_{4}(\mathrm{aq}) \Delta \mathrm{H}^{\circ}=-80 \pm 3 \mathrm{kcal} / \mathrm{mol} \\
& \mathrm{C}=\Delta \mathrm{H}^{0}\left\{\mathrm{H}^{\bullet}(\mathrm{g}) \longrightarrow 1 / 2 \mathrm{H}_{2}(\mathrm{~g})\right\}-\Delta \mathrm{H}^{0}\left\{\mathrm{H}^{\bullet}(\mathrm{g}) \longrightarrow \mathrm{H}^{\bullet}(\mathrm{aq})\right\}-1 / 2 \mathrm{TS}^{0}\left\{\mathrm{H}_{2}(\mathrm{~g})\right\}
\end{aligned}
$$

The affinity of $\mathrm{MnO}_{4}^{-}$for hydrogen atom is equivalent to its affinity for an electron( its redox potential $\mathrm{E}^{0}$ ) and a proton (the acid dissociation constant $\mathrm{K}_{\mathrm{a}}$ of $\mathrm{HMnO}_{4}^{-}$), following the thermo chemical cycle in the above scheme $-1\left[\mathrm{BDE}\left(\mathrm{H}-\mathrm{OMnO}_{3}{ }^{-}\right)=23.06 \mathrm{E}^{0}+1.37 \mathrm{pK}_{\mathrm{a}}+\mathrm{C}\right][69,70]$ Such cycles have been used by 
Bordwell $[72,73]$ and others to determine bond strength to hydrogen in many organic and organometallic compounds $[70,71,72,78]$ above scheme -1 is slightly different from what Kimberly and others used previously $[56,57]$ in part because a recent pulse radiolysis study provided a new value for the $\mathrm{pK}_{\mathrm{a}}$ of $\mathrm{HMnO}_{4}^{-}[68,74,75]$ The constant $\mathrm{C}$ is calculated as $57 \pm 2 \mathrm{kcal} / \mathrm{mol}[69,70,71,72,78]$, with the common assumption that the entropies of $\mathrm{MnO}_{4}^{-}$and $\mathrm{HMnO}_{4}^{-}$are equal [70,71,72] a value of $80 \pm 3 \mathrm{kcal} / \mathrm{mol}$ for the $\mathrm{H}_{-}-\mathrm{OMnO}_{3}$ bond strength is obtained. Alternatively the constant is not needed if relative bond are calculated from a thermodynamic cycle where hydrogen atom is transferred from another species. HA as in equation- 6 ( $\mathrm{HA}=$ $\mathrm{PhOH}$ or $\mathrm{PhNH}_{2}$ ). The standard free energy $\Delta \mathrm{G}^{0}$ is calculated in eq-7, from the known $\mathrm{E}^{0}$ and $\mathrm{K}_{\mathrm{a}}$ values [78,79]_ and is taken to be equal to $\Delta \mathrm{H}^{0}$ because $\Delta \mathrm{S}^{0} \cong 0$. The derived $\Delta \mathrm{H}^{0}$ is the difference between the $\mathrm{H}$ $\mathrm{OMnO}_{3}$ and $\mathrm{HA}$ bond strength. The solution $\mathrm{H}-\mathrm{A}$ bond strength are derived from the gas phase value and estimate of differential salvation of $\mathrm{HA}$ and $\mathrm{A} \cdot$. Both calculation are in good agreement with $\mathrm{D}\left(\mathrm{H}-\mathrm{OMnO}_{3}^{-}\right)=$ $80 \pm 3 \mathrm{kcal} / \mathrm{mol} .[78,79]$

$$
\begin{gathered}
\mathrm{MnO}_{4}+\mathrm{HA} \rightleftharpoons \mathrm{HMnO}_{4}+\mathrm{A}^{\bullet} \\
\Delta \mathrm{H}^{0}=\mathrm{BDE}(\mathrm{H}-\mathrm{A})-\mathrm{BDE}(\mathrm{H}-\mathrm{OMnO} 3)= \\
23.06\left[\mathrm{E}^{0}\left(\mathrm{~A}^{\bullet}\right)-\mathrm{E}^{0}\left(\mathrm{MnO}_{4}\right)\right]+1.37\left[\mathrm{pKa}(\mathrm{HA})-\mathrm{pKa}\left(\mathrm{HMnO}_{4}\right)\right]
\end{gathered}
$$

The O-H bond strength of $80 \mathrm{kcal} / \mathrm{mol}$ in $\mathrm{HMnO}_{4}^{-}$is $9 \mathrm{kcal} / \mathrm{mol}$ less than the $\mathrm{O}-\mathrm{H}$ bond strength in $\mathrm{t}-$ $\mathrm{BuOOH}(89 \mathrm{kcal} / \mathrm{mol})$ [80] and is between the $\mathrm{H}-\mathrm{Br}$ and $\mathrm{H}-\mathrm{I}$ bond strengths of $87 \mathrm{and} 71 \mathrm{kcal} / \mathrm{mol}$. Since t$\mathrm{BuOO} \bullet$ and $\mathrm{Br} \bullet$ readily abstract $\mathrm{H} \bullet$ from alkyl aromatic compounds, it is not surprising that permanganate does as well. (Slower rates can be observed for permanganate because it is a stable species, not a fleeting intermediate.) $\Delta \mathrm{H}^{\circ}$ for the $\mathrm{H} \bullet$ transfer steps the difference between the strengths of the bond being broken and that being formed-is a lower bound for $\Delta \mathrm{H}^{\ddagger}$. Therefore, formation of a strong bond to $\mathrm{H} \bullet$ is a necessary condition for hydrogen atom abstracting reactivity. The reactions discussed here vary from $9 \mathrm{kcal} / \mathrm{mol}$ uphill for $\mathrm{H} \cdot$ abstraction from toluene to $6 \mathrm{kcal} / \mathrm{mol}$ downhill for abstraction from xanthene (as they observed in their experiment). The data suggest that formation of a strong $\mathrm{O}-\mathrm{H}$ bond is not only necessary but also a sufficient condition for $\mathrm{H} \bullet$ abstraction. It is well established that rates of $\mathrm{H} \bullet$ abstraction by main group radical are directly related to bond strengths. $\mathrm{OH} \cdot$ reacts with almost organic compounds at close to the diffusion limit,[81] in part because it forms such a strong bond to $\mathrm{H} \bullet(119 \mathrm{kcal} / \mathrm{mol})$ [80]. tBuOO $\bullet$ is a much less reactive oxidant [82], because it forms a weaker O-H bond of $89 \mathrm{kcal} / \mathrm{mol}$.[80]

Evans and Polanyi suggested in 1936 a linear relationship between activation energies and net enthalpy change in hydrogen atom transfer reactions (equation-8)

$$
E_{\mathrm{a}}=\beta+\alpha(\Delta H) \quad \text { or } \log k \propto \Delta G^{*}=\beta+\alpha(\Delta H)
$$

and this correlation works quite well over a narrow range of $\Delta \mathrm{H}^{\circ}$ for similar radicals and substrates. [73,76,77,83] Over a wider range, $\alpha \rightarrow 0$ as the reactions become very exothermic and $\alpha \rightarrow 1$ as the reactions become very endothermic [66].Kimberly [29] found his data fit the Polanyi eq-8 Well. $\Delta \mathrm{H}^{\ddagger}$ and $\log \mathrm{k}_{2}$ for oxidation of the different arylalkanes by $\mathrm{n}-\mathrm{Bu}_{4} \mathrm{NMnO}_{4}$ are proportional to proportional to $\Delta \mathrm{H}^{\circ}$. The linearity of these relations over the $15 \mathrm{kcal} / \mathrm{mol}$ range of $\Delta \mathrm{H}^{\circ}$ is quite good, given the large uncertainties in some of the $\mathrm{C}-\mathrm{H}$ bond strength. Both $\log \mathrm{k}_{2}$ and $\Delta \mathrm{H}^{\ddagger}$ correlate with $\Delta \mathrm{H}^{\circ}$ because the entropies of activation are essentially constant. These correlations strongly support the assignment of the rate determining step as $\mathrm{H} \cdot$ transfer from carbon to an oxo group. The rate of $\mathrm{H} \bullet$ transfer from alkyl aromatic compounds to $\mathrm{n}-\mathrm{Bu}_{4} \mathrm{NMnO}_{4}$ also correlate with rate of abstraction by $\mathrm{OH} \bullet, \mathrm{BuO} \bullet$ and $\mathrm{BuOO} \bullet[29]$ and suggested $\mathrm{H} \bullet$ transfer terminology.

Oxidation of p-Nitrophenylfluoromethylcarbinol with $\mathrm{NaOH}$ is a good evidence for abstraction of Hydrogen from alkoxide to permanganate ion. [18] Fleming [52] observed that p-Nitrobenzeldehyde oxidized slower than benzaldehyde and exhibited autocatalysis and both autocatalytic and the initial rates were reduced by a factor of about four fold compared to benzaldehyde at $\mathrm{pH} 1.40$, benzaldehyde $\mathrm{K}_{2}=1.64\left(1 \mathrm{~mole}^{-1} \mathrm{sec}^{-1}\right)$ and p-Nitrobenzaldehyde $\mathrm{K}_{2}=0.470\left(1 \mathrm{~mole}^{-1} \mathrm{sec}^{-1}\right)$. This oxidation shows some dependence on Hydrogen ion concentration. The initial rate of oxidation of p-nitrobenzaldehyde is reduced by almost four fold compared to benzaldehyde at the same $\mathrm{pH}$. This is accord with the negative $\rho$-value found by Wiberg and co-workers [11] and the mechanism at high $\mathrm{pH}$ was proposed. 

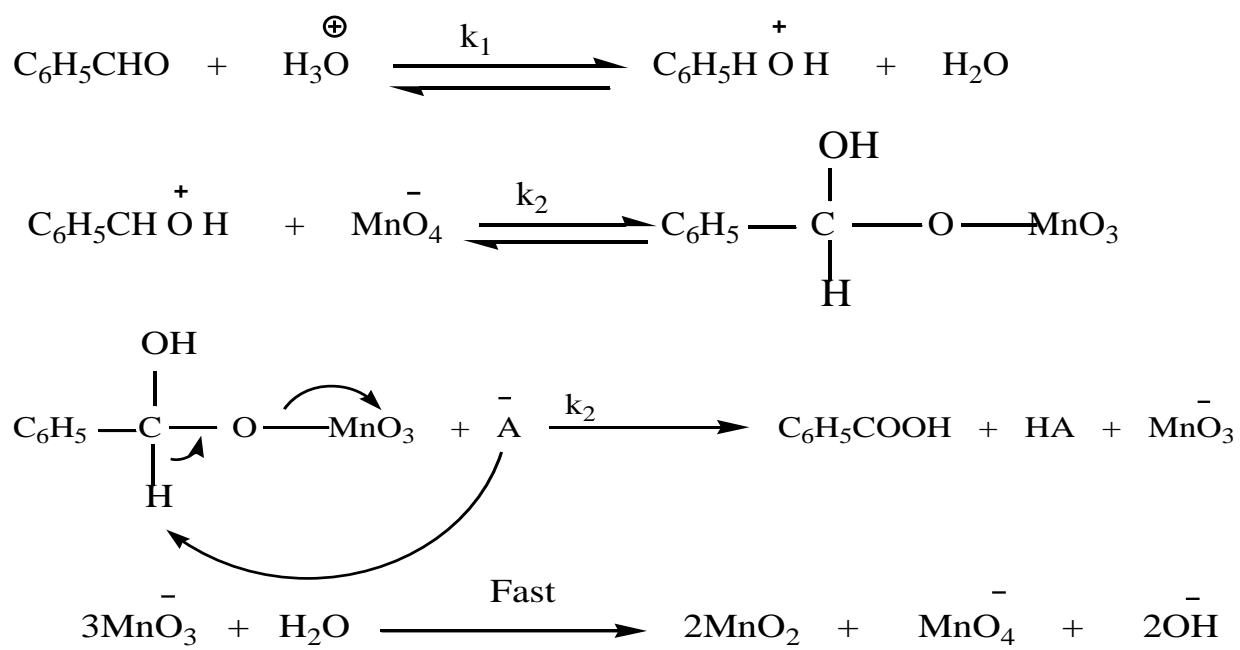

The following mechanism also accommodates the experimental facts found by Wiberg [11] although the $\rho$ value of the reaction would be difficult to predict.

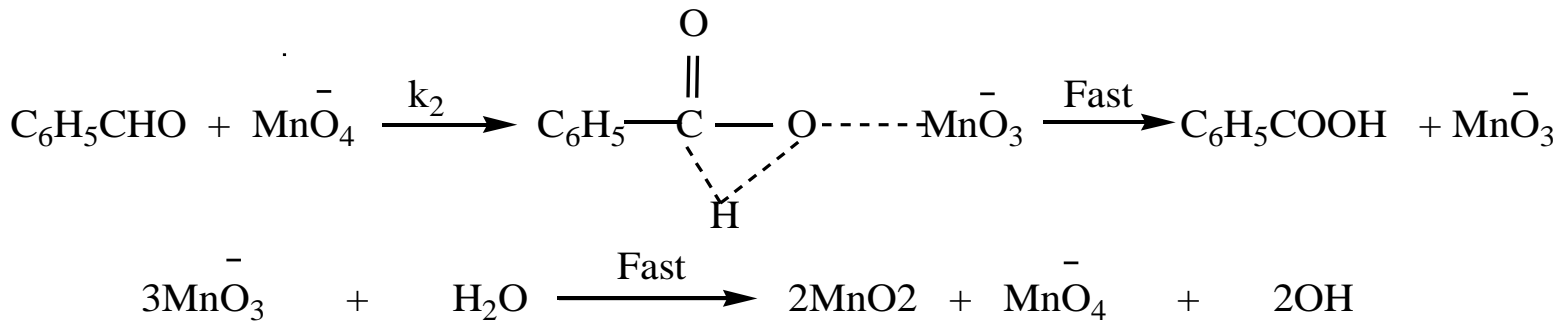

The autocatalytic effect was found to be reduced by almost four fold for the permanganate oxidation of p-Nitrobenzaldehyde compared to benzaldehyde. For both cases, since experimental evidence shown that the system exhibits overoxidation and it is postulated that the benzene ring is undergoing decomposition at later stage in the reaction. The mechanism is reasonable to suggest a radical reaction path. It seems that permanganate oxidation of benzaldehyde and p-nitrobenzaldehyde goes by two paths, i.e. a major one which is responsible for the normal oxidation giving good second order kinetic and minor path which involves a very small percent of a radical species formed by hydrogen atom abstraction by the permanganate ion. The radical then initiates rupture of the benzene ring likely via a chain mechanism.

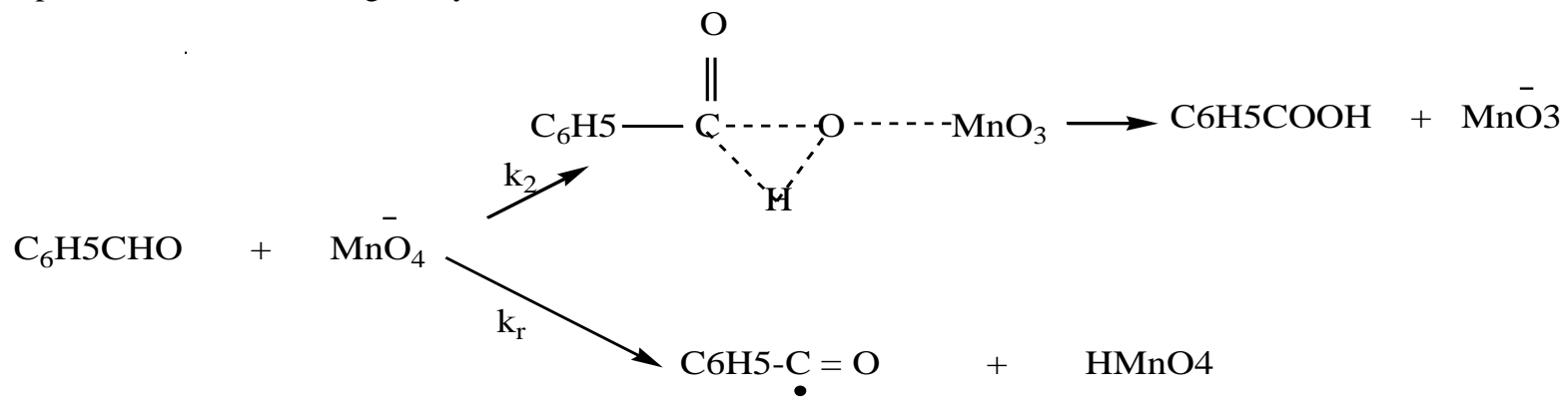

The observed reduction of the over oxidation of p-nitrobenzaldehyde is difficult to explain.

A similar effect [21] in oxidation of p-nitrotoluene compared to the toluene itself that the electron withdrawing effect of the p-nitro group should retard formation of a radical species does not seem plausible. Perhaps once the radical is formed there is sufficient stabilization due to the p-nitro group to retard the chain reaction which results in ring degradation. Such stabilization would result from the following resonance structures.

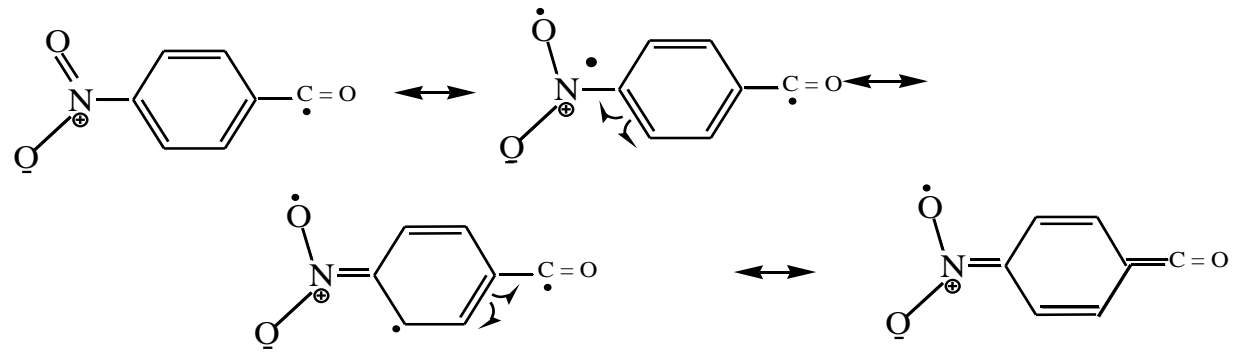


p-nitrophenyltrifluoromethylcarbinols show an enhanced rate of oxidation by potassium permanganate [52]. Other substituted phenyltrifluoromethylcarbinols[18] shown that although the prospect of a hydride transfer occurring in the rate of determining step seemed likely. They found no substituent effect, i.e. p-methoxy gave essentially and same rate as m-nitro. Moreover the enhancement in rate observed for the p-nitro alcohol is further evidence against a hydride transfer occurring. Stewart and linden [18] also listed three termolecular mechanism as possible path for the reaction, but only one of these seems likely since the other two require termolecular solute collisions and will therefore not be considered. The following mechanism they proposed does not require termolecular solute collisions.

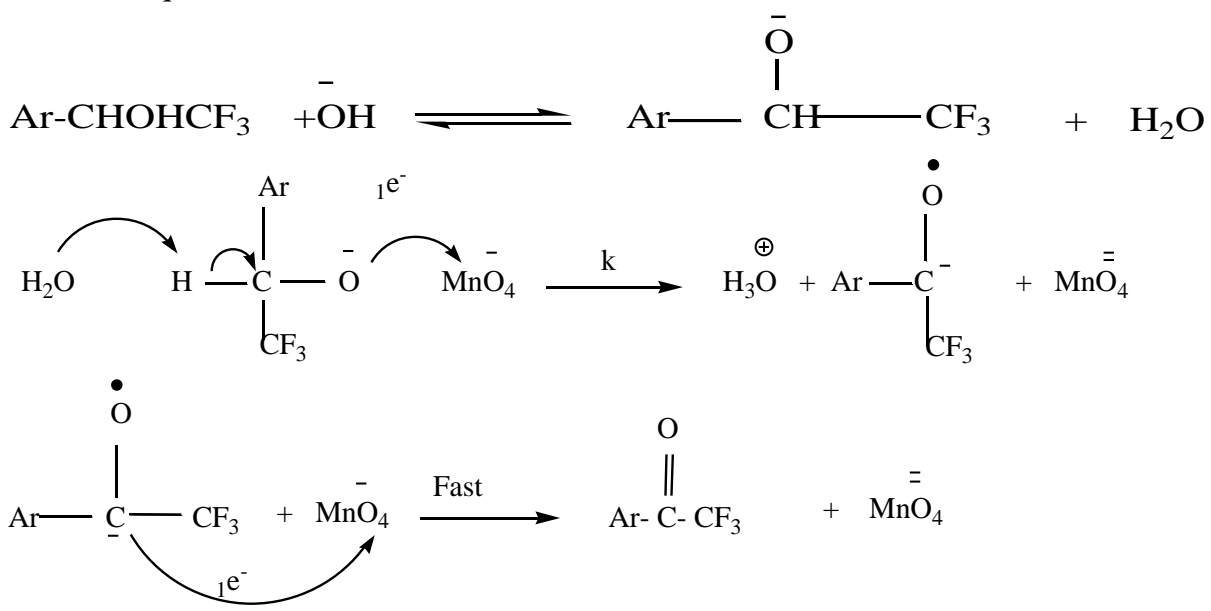

What is involved here is a simultaneous process, electron abstraction by permanganate and proton abstraction by the solvent.

It seems energetically more favourable however, to have a one stage process in the transfer of a hydrogen atom from the alkoxide ion to the permanganate ion. And in addition accommodates the experimental evidence gathered by Stewart [18], including the negligible substituent effect. Moreover, the enhancement in rate observed for the p-nitro alcohol fits very well in to this mechanism in that the p-nitro group would afford enhanced radical stabilization. It has been found in the past that p-nitro group substituents enhance radical reaction as evidence by the large dissociation constant of p-nitro-hexaphenyl-ethane over all other substituent. A mechanism involving Hydrogen atom abstraction by permanganate from the alkoxide ion is thus favoured in view of the result found by Fleming [52] in the permanganate oxidation of p-nitrophenyltrifluoromethylcarbinol.

In fact it seems reasonable to postulate the same mechanism as occurring in the potassium permanganate oxidation of all substituted phenyltrifluoromethylcarbinols and indeed alcohols in general. That $\mathrm{p}$ nitro group should be expected to give an enhancement in rate can be realized from the resonance structures shown with the for the oxidation

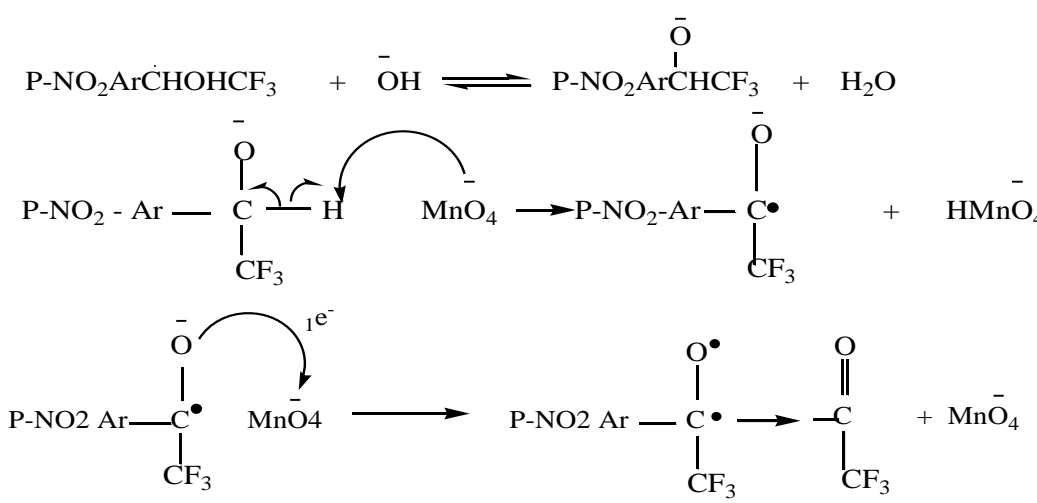

Conclusions

The permanganate oxidation of alkylarenes can undergo by several mechanism. The most common and dominant is hydrogen atom abstraction by permanganate ion. The rate limiting step for the reaction is hydrogen atom transfer from the substrate to manganese oxo group. The enthalpies of activation correlate with the strength of the $\mathrm{C}-\mathrm{H}$ bond being cleaved as is typical of the hydrogen atom abstraction by main group radicals and It is well established that rate of $\mathrm{H}$ atom abstraction by main group radicals are directly related to bond strengths and suggested $\mathrm{H}$ atom transfer terminology.

\section{References:}


[1]. Ciamician G and Silber P. Ber. Dtsch. chem. Ges, 1912, 45, 38

[2]. Binapfel J and Krey W. (IG-Farben AG) Dr-pat, 1931, 522, 255

[3]. Sherwood P W. Petroleum processing, 1953, 8, 905

[4]. Mocek M. Ph.D.thesis University of British Columbia Vancouver, 1962

[5]. Symons M C R and Carrington A. J. Chem. Soc, 1956, 3373

[6]. Verlander D, Blou G and Wallis T. Ann, 1906, 345, 261

[7]. Stamm H, "Newer methods of volumetric analysis" trans by Oesper, Van Nostrand and Co. N Y, 1938

[8]. Symons M C R, J. Chem. Soc, 1953, 3956

[9]. Drummond A Y and Waters W A, J. Chem. Soc, 1953, 435

[10]. Pode J S F and Waters W A, J. Chem. Soc, 1956, 717

[11]. Wiberg K B and Stewart R, J. Am. Chem. Soc, 1955, 77, 1786-1795

[12]. Tronov B Y and Russ J, Phys. Chem, 1927, 59, 1155

[13]. Holluta J and Mutschin A, Z. Physik. Chem, 1930, 150, 381

[14]. Kenyon J and Symons M C R, J. Chem. Soc, 1953, 3580

[15]. Tompkins F C, Trans. frady. Soc, 1945, 39, 280

[16]. Kwart H and Francis P S, Sept. Paper presented at $126^{\text {th }}$ meeting of Am. Chem. Soc, N Y, 1954

[17]. Stewart R, J. Am. Chem. Soc, 1957, 79, 3057-3061

[18]. Linden R V D and Stewart R, Farady. Soc. Disc, 1960, 29, 211

[19]. Linden R V D, Ph.D. thesis, University Of British Columbia Vanvouver, 1960

[20]. Drummond A Y and Waters W A, J. Chem. Soc, (1954 - 2456), (1955 - 2129)

[21]. Cullis C F and Landburd J W, J. Chem. Soc, 1955, (555-560), (1407-1412), (4186-4190)

[22]. Lee D G and Singer B E, Can. J. Chem, 1970, 48, 2674

[23]. Fergusson R H, Lerch W and Day J F, J. Am. Chem. Soc, 1931, 53, 126

[24]. Merz M and Waters W A, J. Chem. Soc, 1949, 15

[25]. Drummond A Y and Waters W A, J. Chem. Soc, 1953, (435-440), 1954, (2456),1955, (2129)

[26]. Land H and Waters W A, J. Chem. Soc, 1957, (4312), 1958, (2129)

[27]. Kharasch M S and Foy M, J. Am. Chem. Soc, 1935, 57, 1510), (1945, 39 280)

[28]. Newman M S, "Steric effects in organic chemistry", John-Wiley and Sons Inc. P, 1956, 591

[29]. Gardner K A, Kuehnert L L and Mayer J M, Inorg. Chem, 1997, 36, 2069-2078

[30]. Spitzer U A, Ph.D thesis, University Of British Columbia, 1972

[31]. Olah G A and Molnar A, Hydrocarbon Chemistry, Wiley Inter science, N Y, 1995

[32]. March J, Advanced organic chemistry $\left(3^{\text {rd }}\right.$ Ed) Wiley Inter science, N Y, 1985

[33]. Trost B M, Comprehensive organic Synthesis Vol.7 (oxidation) Ed Pergamon Press Oxford N Y, 1991

[34]. Waters W A, Q. Rev. (London), 1958, 12, 277-300

[35]. Stewart R and Spitzer U A, Can. J. Chem, 1978, 56, 1273-1279

[36]. Lux H, Z. Naturforsch, 1946,01, 281

[37]. Pode J S F and Waters W A, J. Chem. Soc, 1956, 717

[38]. Ubbelohde A R J P, J. Chem. Soc, 1935, 1605

[39]. Karaman H, Borton R, Robertson BE and Lee D G J, J. org. Chem, 1984, 49, 4509

[40]. Veprek siska J, Ettel V and Regner A, J. Inor. Nucl. Chem, 1964, 26, 1474-1477

[41]. Gardner K A and Mayer J M, Science, 1995, 264, 1849-1851

[42]. Brauman J I and Pandell A J, J. Am. Chem. Soc, 1970, 92, 329-335

[43]. Wiberg K B and Fox A S, J. Am. Chem. Soc, 1963, 85, 3487-3491

[44]. Latimer W M, "The oxidation state of the elements and their potentials in aqueous solution", $2^{\text {nd }}$ ed. Prentice Hall N Y, 1952

[45]. Kochi J K, "Comprehensive organic synthesis" Vol.7 (Oxidation) Trost B M, ed. Pergamon, N Y, 1991, 849-855

[46]. Rappe A K and Goddard W A, J. Am. Chem. Soc, 1982, 104, 3287-3294

[47]. Lee G D and Chen T, J. Am. Chem. Soc, 1993, 115, 11231-11236

[48]. Fatiadi A J, Synthesis Stuttgart, 1987, 85-127

[49]. Avila D V, Brown C E, Ingold K U and Lusztyk J J, J. Am. Chem. Soc, 1993, 115, 466-470

[50]. Wayner D D M and Arnold D R, Can. J. Chem, 1985, 63, 2378

[51]. Gould E S, "Mechanism and structure in organic chemistry", H Holt and Co. N Y, 1959, 675

[52]. Fleming D G, M.Sc.Thesis University of British Columbia Vancouver Canada, 1963

[53]. Guyard A, Bull. Soc. Chem. France, 1864, 6, 89

[54]. Ladbury J W and Cullis C F, Chem. Revs, 1958, 58, 403

[55]. Swain C G, Will R A and Bader R F W, J. Am. Chem. Soc, 1961, 83, 1945-1951

[56]. Cook G K and Mayer J M, J. Am. Chem. Soc, 1994, 116, 1855-1868

[57]. Cook G K and Mayer J M, J. Am. Chem. Soc, 1995, 117, 1739-1756

[58]. K.A.Gardner K A and Mayer J M, Science, 1995, 267, 1849-1851

[59]. Stubbe J and Kozarich J W, Chem. Rev, 1986, 19, 383-391

[60]. Stewart C L and Klinman J P 1988 Annu.Rev.Biochem. 57 551-592

[61]. Tian G, Berry J A and Klinman J P, Biochemistry, 1994, 33, 226-234

[62]. Blasse G, Struct. Bonding (Berlin), 1980, 42, 1-42 (specially page-11)

[63]. Ruchardt C, Gerst M and Nolke M, Angew. Chem. Int. Ed. Eng, 1992, 31, 1523-1525

[64]. Gerst M, Morgenthaler J and Ruchardt C, Chem. Ber, 1994, 172, 691-696

[65]. Harmony J A K, Methods free radical Chem, 1974, 5, 101-173

[66]. Lowry R H and Richardson K S, "A theoretical and physical principles of organic reactivity", Wiley N Y, 1995, 175-182

[67]. Hecht S M, Acc. Chem. Res, 1986, 19, 383-391

[68]. Rush J D and Bielski B H, Inorg. Chem, 1995, 34, 5832-5838

[69]. Wayner D D M, Lusztyk E, Page D, Ingold K U, Mulder P, Larrhoven L J J and Aldrich H S, J. Am. Chem. Soc, 1995, 117, 87378744

[70]. Parker V D, J. Am. Chem. Soc, 1992, 114, 7458-7462

[71]. Bordwell F G, Cheng J P, Ti G Z, Satish A V and Zhang X, J. Am. Chem. Soc, 1991, 113, 9790-9795

[72]. Bordwell F G and Liu W Z, J. Am. Chem. Soc, 1996, 118, 8777-8781

[73]. Korzekwa K R, Jones J P and Gillette J R, J. Am. Chem. Soc, 1990, 112, 7042-7046 
[74]. Lister M W and Yoshino Y, Can. J. Chem, 1960, 38, 2342-2348

[75]. Heckner K H and Landsberg R, J. inorg. Chem, 1967, 19, 423-430

[76]. Korcek S, Chenier J H B, Haward J A and Ingold K U, Can. J. Chem, 1972, 50, 2285-2297

[77]. Tedder J M, Angew. Chem. Int. Ed. Engl, 1982, 21, 401-410

[78]. Jonsson M, Lind J, Eriksen T E and Merenyi G J, J. Am. Chem. Soc, 1994, 116, 1423-1427

[79]. Lind J, Shen X, Eriksen T E and Merenyi G J, J. Am. Chem. Soc, 1990, 112, 479-482

[80]. Colussi A J, "In chemical kinetics of small organic radicals", Z B Alfassi, ed, CRC press, Boca Raton F L, 1988, 33

[81]. Buxton V G, Greenstock C L, Helman W P and Ross A B, J. Phys. Chem, 1988, 17, 513

[82]. Mulder P, Arends I W C E, Clark K B and Wayner D D M, J. Phys. Chem, 1995, 99, 8182-8189

[83]. Ingold K U, "Free radical", Kochi, J K, ed. Wiley N Y, 1973, 1, chapter-2, 69

[84]. Symons M C R, Chem. Rev, 1963, 63, 433-460

[85]. Exner O, "In advance in linear free energy relationships", Chapman N B Shorter J, ed, Plenum press London, 1972, 20

[86]. JANAF "Thermochemical tables", $3^{\text {rd }}$ ed, J. Phys. Chem, 1984, 14, Suppl. 1 